\title{
Application of Gas Condensing Boilers in Domestic Heating
}

\author{
Marija ŽIVIĆ, Antun GALOVIĆ, Jurij AVSEC, Antun BARAC
}

\begin{abstract}
A growing number of households have had condensing boilers built in to be used for the heating of spaces and for the hot water supply. The use of condensing boilers is justified from the point of view of energy because they achieve higher thermal efficiency than traditional boilers. Condensation of water vapour occurs in the flue gases, whereby the heat released by condensation is used to heat the water in the boiler. How much water vapour will condense depends on the temperature to which the flue gases are cooled. In this paper, a thermodynamic analysis of thirteen built-in gas condensing boilers was performed; data on the flue gas composition and temperature, as well as on the excess air required for combustion were obtained for that purpose. The calculation results consisting of the amount of condensed water, the thermal efficiency of the boiler, and the volume flow rates of the air and fuel are presented in tables. The analysis identified the cases in which the water vapour condensation occurred and determined the amount of the condensed water. The cases without water vapour condensation were also identified.
\end{abstract}

Keywords: gas condensing boilers; thermodynamic analysis; thermal efficiency of the boiler

\section{INTRODUCTION}

Boilers for central heating and hot water supply consume a considerable amount of energy from primary sources, while combustion products pollute the environment. Therefore, the aim is to increase the boiler thermal efficiency and to reduce the emission of greenhouse gases to the environment. Condensing technology makes better use of thermal energy produced by fuel combustion. The advantage of condensing boilers is that the flue gases produced by combustion are cooled to the temperature below the temperature of water vapour condensation (below the dew point) and the heat released by the resulting condensation is used for the additional heating of water. Thus, the boiler thermal efficiency is increased by $10 \%$. Research has shown that components of flue gases, such as sulphur and nitrogen compounds $\left(\mathrm{SO}_{2}\right.$ and $\mathrm{NO}_{\mathrm{x}}$ ) and particulate matter, can be partially or even completely solved in the condensed water, so that the environmental pollution is significantly reduced, [1]. Due to the above mentioned advantages, condensing boilers play a major role in energy savings and environmental protection.

Among primary fuels, natural gas is the most suitable fuel for condensing devices, [2]. By combusting natural gas, the mole fraction of water vapour in flue gases is about $20 \%$, which is much more than for other fuels. A larger amount of water vapour in flue gases means that more heat can be released when the flue gases are cooled to the required temperature for condensation; as a result, the boiler thermal efficiency can be increased.

Wider use of condensing boilers in heating systems is hindered by the fact that the high thermal efficiency of a boiler is achieved only if the temperature of the water in the return pipe is low. The temperature of flue gases has to drop below the dew point temperature in order to benefit from the high efficiency thus achieved. Consequently, the recovery of latent heat of vaporisation depends on the existence of a consumer that requires low-temperature heat.

Research has shown that the water temperature in the return pipe between 40.8 and $53.3{ }^{\circ} \mathrm{C}$ is related to an increase in the thermal efficiency between $2.12 \%$ and $5.76 \%$, [3].
The application of condensing boilers, their advantages and disadvantages have been described in several studies. The central heating system for the hot water supply to thirteen buildings was monitored to analyse heat losses and seasonal performance of condensing boilers, [4]. A new, low-temperature heating system with nominal temperatures of $45^{\circ} \mathrm{C}$ in the supply pipes and of $35{ }^{\circ} \mathrm{C}$ in the return pipes is described in [5]. On the other hand, the study [6] gives a description of the technology required for the recovery of large amounts of lowtemperature heat available from flue gases of large industrial condensing boilers.

According to a European regulation, it is mandatory to install condensing boilers in new systems and to replace obsolete standard boilers by them. This regulation has also been accepted by the Republic of Croatia. In accordance with the Commission Regulation (EU) No. 813/2013 of 2 August 2013 implementing Directive 2009/125/EC of the European Parliament and of the Council with regard to ecodesign and requirements for space heaters and combination heaters, the energy efficiency of the seasonal space heating and the efficiency of heaters should not be less than $86 \%$ for residential natural gas/fuel oil boilers and combination boilers of $\leq 70 \mathrm{~kW}$ rated thermal power except in the case of B1 boilers of $\leq 10 \mathrm{~kW}$ rated thermal power and B1 combination boilers of $\leq 30 \mathrm{~kW}$ rated thermal power. In addition, from September of 2018 non-condensing devices will have to satisfy an additional requirement regarding the level of $\mathrm{NO}_{x}$ emissions of $\leq 56 \mathrm{mg} / \mathrm{kWh}$.

A substantial number of condensing boilers have been installed over the past few years. This is the reason why a thermodynamic analysis of thirteen condensing boilers fuelled by gas was performed; the analysis results are presented in this paper. Relevant data on the composition and temperature of flue gases have been obtained from measurements performed by gas service providers in the Osijek-Baranja County. The data on the composition of natural gas (expressed in mole and mass fractions) as well as on its heating value have been taken from the laboratory gas quality reports for specific points (Našice) publicized on the Plinacro, Ltd. web site. 


\section{MEASURED DATA}

Data on the natural gas composition (expressed in molar and mass fractions) shown in Tab. 1 have been obtained by chromatography. The analysis was conducted in accordance with the HRN EN ISO 6974-5:2014 standard.

Table 1 Components of natural gas (mass and mole fractions); sample "Našice", 10 January 2017 at $11: 40 ; p=26$ bar

\begin{tabular}{|c|c|c|}
\hline Component & $\begin{array}{c}\text { Massfraction, } \\
\mathrm{x}_{\mathrm{i}}, \mathrm{kg} / \mathrm{kg} ; \%\end{array}$ & $\begin{array}{c}\text { Mole fraction, } \\
y_{i}, \mathrm{~mol} / \mathrm{mol} ; \%\end{array}$ \\
\hline $\mathrm{N}_{2}$ & 2.89 & 1.75 \\
\hline $\mathrm{CO}_{2}$ & 0.26 & 0.10 \\
\hline $\mathrm{C}_{1}$ & 89.16 & 94.14 \\
\hline $\mathrm{C}_{2}$ & 6.20 & 3.49 \\
\hline $\mathrm{C}_{3}$ & 1.02 & 0.39 \\
\hline $\mathrm{i}-\mathrm{C}_{4}$ & 0.17 & 0.05 \\
\hline $\mathrm{n}-\mathrm{C}_{4}$ & 0.17 & 0.05 \\
\hline $\mathrm{i}-\mathrm{C}_{5}$ & 0.04 & 0.01 \\
\hline $\mathrm{n}-\mathrm{C}_{5}$ & 0.04 & 0.01 \\
\hline $\mathrm{C}_{6+}$ & 0.05 & 0.01 \\
\hline & &
\end{tabular}

Tab. 2 shows the values of natural gas properties measured according to the HRN EN ISO 6976:2008 standard.

Table 2 Values of natural gas properties measured in the "Našice" sample

\begin{tabular}{|l|c|c|}
\cline { 2 - 3 } \multicolumn{1}{c|}{} & \multicolumn{2}{c|}{ Conditions } \\
\cline { 2 - 3 } \multicolumn{1}{c|}{} & $\left(15 / 15^{\circ} \mathrm{C}\right)$ & $\left(25 / 0^{\circ} \mathrm{C}\right)$ \\
\hline Higher heating value, $\mathrm{MJ} / \mathrm{m}^{3}$ & 38.42 & 40.51 \\
\hline Lower heating value, $\mathrm{MJ} / \mathrm{m}^{3}$ & 34.64 & 36.55 \\
\hline Wobbe number, $\mathrm{MJ} / \mathrm{m}^{3}$ & 50.19 & 52.91 \\
\hline Density, $\mathrm{kg} / \mathrm{m}^{3}$ & 0.7180 & 0.7577 \\
\hline Relative density $(\mathrm{air}=1)$ & 0.5859 & 0.5861 \\
\hline Molar mass, $\mathrm{kg} / \mathrm{kmol}$ & \multicolumn{2}{c|}{16.940} \\
\hline Gas constant, $\mathrm{J} / \mathrm{kg} \cdot \mathrm{K})$ & \multicolumn{2}{c|}{490.81} \\
\hline
\end{tabular}

When servicing the condensing gas boilers installed in Našice and its surroundings, the Osijek-Baranja County, the service providers measured the flue gas composition using a MRU Delta 65 flue gas analyser. The measured values for thirteen boilers under consideration are shown in Tab. 3 .

As one can see from Tab. 3, the values of outlet temperatures of flue gases $\left(\vartheta_{\text {f.gas,out }}\right)$ are different. The obvious conclusion is that condensation of water vapour from flue gases will occur in the operation of some boilers and that it will not occur in the operation of other boilers. Here, it is assumed that the flue gas pressure at the boiler outlet is equal to atmospheric pressure.

Table 3 Measured values of air temperature, flue gas outlet temperature, and excess air

\begin{tabular}{|c|c|c|c|c|c|}
\hline $\begin{array}{c}\text { Boiler } \\
\text { No. }\end{array}$ & Date & $\begin{array}{c}\text { Rate of heat } \\
\text { output }(\mathrm{kW})\end{array}$ & $\begin{array}{c}\vartheta_{\text {air,in }} \\
\left({ }^{\circ} \mathrm{C}\right)\end{array}$ & $\begin{array}{c}\vartheta_{\text {f.gas,out }} \\
\left({ }^{\circ} \mathrm{C}\right)\end{array}$ & Excessair, $\lambda$ \\
\hline 1 & $29 / 11 / 2016$ & 25 & 14.7 & 69.3 & 1.33 \\
\hline 2 & $05 / 12 / 2016$ & 30 & 23.0 & 71.0 & 1.34 \\
\hline 3 & $14 / 12 / 2016$ & 24 & 16.4 & 82.2 & 1.32 \\
\hline 4 & $4 / 1 / 2017$ & 35 & 17.9 & 35.1 & 1.35 \\
\hline 5 & $4 / 1 / 2017$ & 25 & 18.4 & 50.6 & 1.35 \\
\hline 6 & $11 / 1 / 2017$ & 24 & 19.3 & 64.4 & 1.36 \\
\hline 7 & $16 / 1 / 2017$ & 30 & 16.3 & 40.6 & 1.34 \\
\hline 8 & $17 / 1 / 2017$ & 30 & 14.6 & 60.4 & 1.34 \\
\hline 9 & $19 / 1 / 2017$ & 30 & 11.3 & 50.0 & 1.35 \\
\hline 10 & $27 / 1 / 2017$ & 20 & 16.0 & 23.5 & 1.33 \\
\hline 11 & $30 / 1 / 2017$ & 24 & 16.8 & 54.4 & 1.34 \\
\hline 12 & $7 / 2 / 2017$ & 24 & 21.8 & 61.7 & 1.34 \\
\hline 13 & $7 / 22017$ & 30 & 22.7 & 35.1 & 1.46 \\
\hline
\end{tabular}

\section{DEVELOPMENT OF A MATHEMATICAL MODEL}

Fig. 1 shows a schematic view of the boiler from which, by applying the first law of thermodynamics and the law of mass conservation for an open stationary system, one can obtain relevant equations for the thermodynamic analysis of operation of the indicated gas boilers.

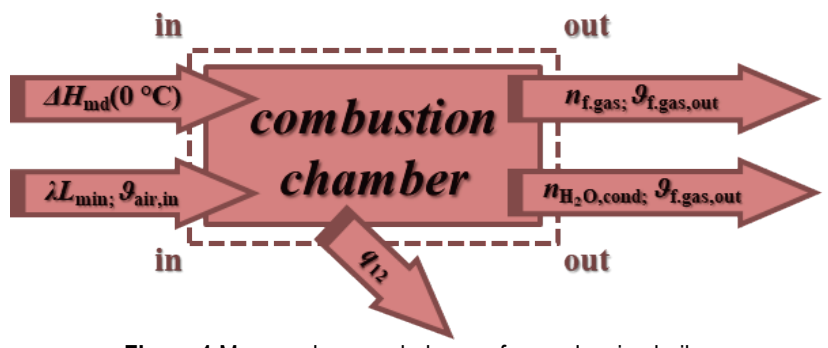

Figure 1 Mass and energy balance of a condensing boiler

The above "thermodynamic" scheme of the burner is reduced to the unit volume flow rate of the fuel; thus, according to the scheme shown above, the first law of thermodynamics for the considered control volume can be written in the following form

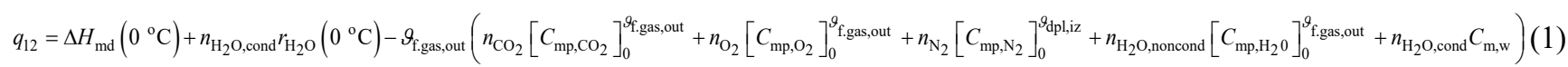

Specific heat rejected to the water is equal to the difference between the sum of the lower heating value of methane and specific heat of condensation and the sensible heat of flue gases. Eq. (1) has been derived for a general case which implies the condensation of water vapour from the flue gas on the surfaces of the flue gas heat exchanger. Condensation occurs if the temperature of water vapour saturation is higher than the temperature of the flue gas at the boiler outlet, or if the pressure of water vapour saturation for the flue gas outlet temperature is lower than the partial pressure of water vapour in the flue gas. The partial pressure of water vapour is calculated according to the Eq. (2).

$$
p_{\mathrm{H}_{2} \mathrm{O}}^{\prime}=y_{\mathrm{H}_{2} \mathrm{O}} p=\frac{n_{\mathrm{H}_{2} \mathrm{O}}}{n_{\text {f.gas }}} p=\frac{n_{\mathrm{H}_{2} \mathrm{O}}}{n_{\mathrm{H}_{2} \mathrm{O}}+n_{\mathrm{N}_{2}}+n_{\mathrm{CO}_{2}}+n_{\mathrm{O}_{2}}} p(2)
$$

while the water vapour saturation pressure, which depends on the absolute (thermodynamic) temperature and, thus, on the outlet temperature of the flue gas, is determined according to [7] by the following equation

$$
\ln \frac{p_{\mathrm{s}}\left(T_{\text {f.gas,out }}\right)}{p_{\text {tr, } \mathrm{H}_{2} \mathrm{O}}}=25.08-\frac{6850.98}{T_{\text {f.gas }, \text { out }}}-5.265 \ln \frac{T_{\text {f.gas,out }}}{T_{\text {tr }, \mathrm{H}_{2} \mathrm{O}}}
$$

In Eq. (3), the temperature of the triple point of water is $T_{\text {tr }}=273.16 \mathrm{~K}$; the value of saturation pressure is expressed in bar. 
At the pressure $p_{\mathrm{s}}\left(T_{\mathrm{f} \text {.gas,out }}\right)$, the amount of water vapour that has not condensed can be obtained from the following equation

$n_{\mathrm{H}_{2} \mathrm{O} \text {,noncond }}=\left(n_{\mathrm{CO}_{2}}+n_{\mathrm{N}_{2}}+n_{\mathrm{O}_{2}}\right) \frac{p_{\mathrm{s}}\left(T_{\text {f.gas,out }}\right)}{1-p_{\mathrm{s}}\left(T_{\text {f.gas }, \text { out }}\right)}$

Consequently, the amount of condensed water vapour is

$n_{\mathrm{H}_{2} \mathrm{O} \text {,kond }}=n_{\mathrm{H}_{2} \mathrm{O}}-n_{\mathrm{H}_{2} \mathrm{O}, \text { noncond }}$

Using the data on the molar fractions of gas components in the fuel from Tab. 1, one can calculate the total amount of water vapour according to the following equation

$$
\begin{aligned}
& n_{\mathrm{H}_{2} \mathrm{O}}= \\
& =2 y_{\mathrm{C}_{1}}+3 y_{\mathrm{C}_{2}}+4 y_{\mathrm{C}_{3}}=2 y_{\mathrm{CH}_{4}}+3 y_{\mathrm{C}_{2} \mathrm{H}_{6}}+4 y_{\mathrm{C}_{3} \mathrm{H}_{8}}
\end{aligned}
$$

The amount of carbon dioxide is also determined using the data on the fuel composition

$$
\begin{aligned}
& n_{\mathrm{CO}_{2}}=\mathrm{CO}_{2}+y_{\mathrm{C}_{1}}+2 y_{\mathrm{C}_{2}}+3 y_{\mathrm{C}_{3}}= \\
& =\mathrm{CO}_{2}+y_{\mathrm{CH}_{4}}+2 y_{\mathrm{C}_{2} \mathrm{H}_{6}}+3 y_{\mathrm{C}_{3} \mathrm{H}_{8}}
\end{aligned}
$$

The amount of oxygen and nitrogen in the flue gas is determined using the following equations

$$
\begin{aligned}
& n_{\mathrm{O}_{2}}=(\lambda-1) \mathrm{O}_{\min }=(\lambda-1)\left(2 y_{\mathrm{C}_{1}}+3,5 y_{\mathrm{C}_{2}}+5 y_{\mathrm{C}_{3}}\right)= \\
& =(\lambda-1)\left(2 y_{\mathrm{CH}_{4}}+3.5 y_{\mathrm{C}_{2} \mathrm{H}_{6}}+5 y_{\mathrm{C}_{3} \mathrm{H}_{8}}\right) \\
& n_{\mathrm{N}_{2}}=\mathrm{N}_{2}+0.79 \lambda \frac{O_{\min }}{0.21}
\end{aligned}
$$

The mean heat capacity per mole of flue gas components in dependence on the flue gas outlet temperature $\vartheta=\vartheta_{\text {f.gas,out }}$ is calculated as follows

$$
\begin{aligned}
& C_{\mathrm{mp}, \mathrm{CO}_{2}}=-0.000003 \vartheta^{2}+0.0139 \vartheta+37.35 \\
& C_{\mathrm{mp}, \mathrm{H}_{2} \mathrm{O}}=-0.0000004 \vartheta^{2}+0.0064 \vartheta+32.835 \\
& C_{\mathrm{mp}, \mathrm{O}_{2}}=-0.000006 \vartheta^{2}+0.0043 \vartheta+29.302 \\
& C_{\mathrm{mp}, \mathrm{N}_{2}}=-0.0000003 \vartheta^{2}+0.003 \vartheta+28.668
\end{aligned}
$$

The temperature in Eqs. (10)-(13) is expressed in ${ }^{\circ} \mathrm{C}$; thus, the values of heat capacity are obtained in $\mathrm{kJ} /(\mathrm{kmol} \cdot \mathrm{K})$

The inlet air enthalpy is determined in a way that atmospheric air is assumed to be a mixture containing 79 mole $\%$ of $\mathrm{N}_{2}$ and 21 mole $\%$ of $\mathrm{O}_{2}$; the heat capacity values corresponding to the inlet air temperature are determined using Eqs. (12) and (13).

The molar lower heating value of natural gas is determined using the equation stated below

$$
\begin{aligned}
& \Delta H_{\mathrm{md}}\left(0^{\circ} \mathrm{C}\right)=y_{\mathrm{CH}_{4}} \Delta H_{\mathrm{md}, \mathrm{CH}_{4}}\left(0^{\circ} \mathrm{C}\right)+ \\
& +y_{\mathrm{C}_{2} \mathrm{H}_{6}} \Delta H_{\mathrm{md}, \mathrm{C}_{2} \mathrm{H}_{6}}\left(0^{\circ} \mathrm{C}\right)+y_{\mathrm{C}_{3} \mathrm{H}_{8}} \Delta H_{\mathrm{md}, \mathrm{C}_{3} \mathrm{H}_{8}}\left(0^{\circ} \mathrm{C}\right)
\end{aligned}
$$

where the following values have been used for the corresponding heating values per kilomole of natural gas:

$$
\begin{aligned}
& \Delta H_{\mathrm{md}, \mathrm{CH}_{4}}\left(0^{\circ} \mathrm{C}\right)=800709 \mathrm{~kJ} / \mathrm{kmol} \\
& \Delta H_{\mathrm{md}, \mathrm{C}_{2} \mathrm{H}_{6}}\left(0^{\circ} \mathrm{C}\right)=800709 \mathrm{~kJ} / \mathrm{kmol} \\
& \Delta H_{\mathrm{md}, \mathrm{C}_{3} \mathrm{H}_{8}}\left(0^{\circ} \mathrm{C}\right)=800709 \mathrm{~kJ} / \mathrm{kmol}
\end{aligned}
$$

In addition, the following values have been used for the heat of condensation per mole of water and the molar heat capacity of liquid water:

$r_{\mathrm{m}, \mathrm{H} 2 \mathrm{O}}=45000 \mathrm{~kJ} / \mathrm{kmoland} C_{\mathrm{m}, \mathrm{w}}=75.37 \mathrm{~kJ} /(\mathrm{kmol} \cdot \mathrm{K})$

Eqs. (2) to (14) and other relevant numerical data presented enable us to determine, for each case investigated, the specific heat flow $\left(q_{12}\right)$ transferred from the flue gas to the cooling water for the purpose of space heating. From these data, one can determine the boiler thermal efficiency according to the following equation:

$$
\eta=\frac{q_{12}}{\Delta H_{\mathrm{md}}\left(0^{\circ} \mathrm{C}\right)+n_{\mathrm{H}_{2} \mathrm{O}, \text { cond }} r_{\mathrm{m}, \mathrm{H}_{2} \mathrm{O}}}
$$

According to this equation, the boiler efficiency cannot exceed $100 \%$; this is only logical since the heat transferred to the flue gas in the burner is not divided only by the molar lower heating value of the fuel, as it is often stated in manufacturers' catalogues; as a matter of fact, this heat is divided by the sum comprising the molar lower heating value of the fuel and the heat released by the condensation of water vapour.

As the rate of heat output ( $\Phi_{\text {boiler }}$ ) of every boiler is known, it is possible to calculate the volume flow rate of natural gas which is combusted using the following expression:

$q_{\mathrm{nG}}=\frac{\Phi_{\text {boiler }}}{q_{12}}$

also, assuming that the pressure of natural gas is 1 bar and its temperature $15^{\circ} \mathrm{C}$, one can easily calculate the volume flow rate of natural gas per hour (consumption per hour expressed in $\mathrm{m}^{3} / \mathrm{h}$ ) using

$q_{\mathrm{V}, \mathrm{G}}=3600 q_{\mathrm{nG}} \frac{R_{\mathrm{m}} T}{p}=3600 \cdot \frac{8314 \cdot 288.15}{1 \cdot 10^{5}} q_{\mathrm{nG}}=23.97 q_{\mathrm{nG}}$

The volume flow rate of condensed water vapour, $q_{\mathrm{v}, \mathrm{c}}$ in $1 / \mathrm{h}$, can be calculated using the equation below

$$
\begin{aligned}
& q_{\mathrm{V}, \mathrm{k}}=q_{\mathrm{nG}} n_{\mathrm{H}_{2} \mathrm{O}, \text { cond }} \cdot 18 \cdot 3600 \cdot v_{\mathrm{H}_{2} \mathrm{O}}\left(\vartheta_{\text {f.gas,out }}\right)= \\
& =64800 \cdot q_{\mathrm{nG}} n_{\mathrm{H}_{2} \mathrm{O}, \text { cond }} v_{\mathrm{H}_{2} \mathrm{O}}\left(\vartheta_{\text {f.gas,out }}\right)
\end{aligned}
$$


where $\left(\vartheta_{\text {f.gas,out }}\right)$ is the specific volume of condensed water vapour in $\mathrm{m}^{3} / \mathrm{kg}$ at the 1 bar pressure and the $\vartheta_{\text {f.gas,out }}$ temperature.

\section{CALCULATION RESULTS}

Based on the mathematical model presented above, an algorithm for calculating the required parameters of the tested boilers was made. The results of the thermodynamic analysis are given in Tab. 4.

$Y$ represents the ratio (in percentages) of the heat released by the condensation of water vapour and the lower heating value of the fuel

$$
Y=\frac{n_{\mathrm{H}_{2} \mathrm{O}, \text { cond }} \cdot 45000}{\Delta H_{\mathrm{md}}\left(0^{\circ} \mathrm{C}\right) \cdot 100 \%}
$$

From Tab. 4, one can see that only six of thirteen tested boilers operated in the condensing mode, while in the remaining seven boilers there were no conditions for condensation to occur. Although the boilers were tested in winter conditions, at low outdoor temperatures (most boilers were tested in January 2017), the seven boilers listed in the table operated without recovering the heat from the condensation of water vapour from flue gases. The efficiency of boilers with no condensation did not exceed $98 \%$, while the efficiency of condensing boilers was as high as $99.67 \%$, depending on the rate of condensation. It should be noted that the boiler efficiency is defined by equation (15) in which the heat transferred to the flue gases is divided by the sum of the lower heating value of fuel and the heat released by condensation.

Table 4 Thermodynamic analysis results

\begin{tabular}{|c|c|c|c|c|c|c|}
\hline No. & $y_{\mathrm{O} 2}, \%$ & $y_{\mathrm{CO} 2}, \%$ & $\eta, \%$ & $q_{\mathrm{v}, \mathrm{g}}, \mathrm{m}^{3} / \mathrm{h}$ & $q_{\mathrm{v}, \mathrm{k}}, 1 / \mathrm{h}$ & $Y, \%$ \\
\hline 1 & 5.643 & 8.649 & 97.38 & 2.457 & No condensation & \\
\hline 2 & 5.767 & 8.579 & 97.63 & 2.941 & No condensation & \\
\hline 3 & 5.517 & 8.72 & 96.87 & 3.371 & No condensation & \\
\hline 4 & 5.889 & 8.51 & 99.11 & 3.176 & 3.089 & 6.427 \\
\hline 5 & 5.889 & 8.51 & 97.74 & 2.415 & 0.4972 & 1.36 \\
\hline 6 & 6.009 & 8.443 & 97.76 & 2.35 & No condensation & \\
\hline 7 & 5.767 & 8.579 & 98.67 & 2.768 & 2.15 & 5.13 \\
\hline 8 & 5.767 & 8.579 & 97.78 & 2.936 & No condensation & \\
\hline 9 & 5.889 & 8.51 & 97.52 & 2.896 & 0.7218 & 1.646 \\
\hline 10 & 5.643 & 8.649 & 99.67 & 1.774 & 2.215 & 8.248 \\
\hline 11 & 5.767 & 8.579 & 98.16 & 2.34 & No condensation & \\
\hline 12 & 5.767 & 8.579 & 98.02 & 2.343 & No condensation & \\
\hline 13 & 7.113 & 7.821 & 99.24 & 2.725 & 2.522 & 6.111 \\
\hline
\end{tabular}

Tab. 3 shows that all the tested boilers operate with a relatively high amount of excess air (greater than 1.3), with a relatively low temperature of condensation as a result. Using Eq. (2), one can calculate the effect of excess air on the temperature of water vapour condensation; the results are shown in the left diagram in Fig. 2.
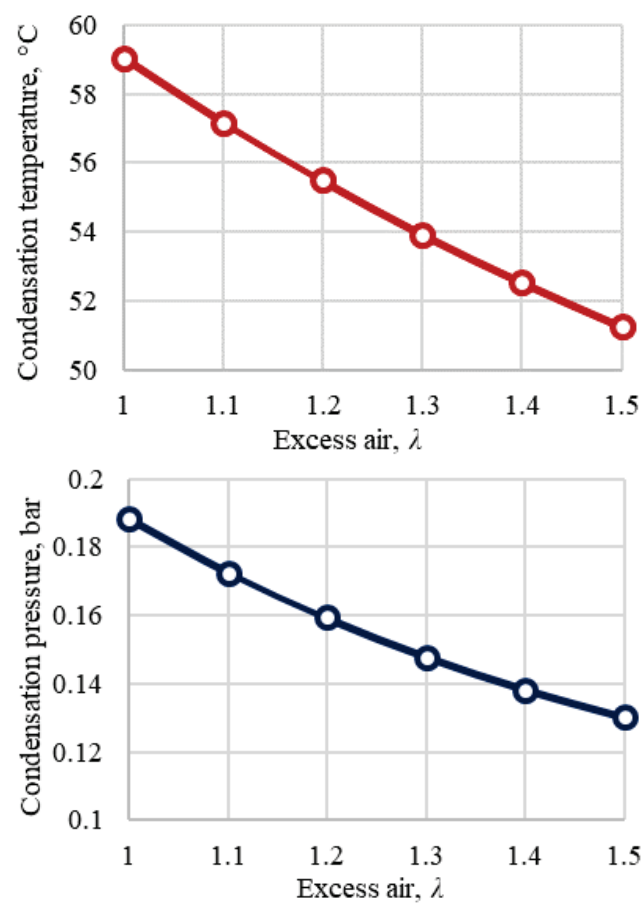

Figure 2 Effect of the excess air on the temperature (top) and pressure (bottom) of water vapour condensation
In that diagram, one can see that the temperature of water vapour condensation decreases with an increase in the amount of excess air $\lambda$, which is in accordance with the laws of physics since the increase in the excess air $\lambda$ entails an increase in the amount of flue gases, while the amount of water vapour remains the same. For example, if the excess air $\lambda=1.0$, the temperature of water vapour condensation in flue gases is $59{ }^{\circ} \mathrm{C}$, while for $\lambda=1.32-1.35$ (these are the values measured in the study and shown in Tab. 3), the values of the temperature of water vapour condensation are in the $53-54{ }^{\circ} \mathrm{C}$ range.

\section{CONCLUSIONS}

The gas boilers, in which no condensation occurred during the test, operated in heating systems in which the consumer could not use the heat at a sufficiently low temperature. This means that the return water temperature was relatively high, above $55^{\circ} \mathrm{C}$, so that the condensation of water vapour from the flue gas did not occur. This can mean that the heat transfer surface area installed on the radiator side was not large enough to cool the water to the temperature below the water vapour dew point or that it was necessary to set the heating system to temperatures above $80 / 60{ }^{\circ} \mathrm{C}$. For a more detailed analysis of the tested condensing boilers one would require data on the water temperature in the radiators. According to the catalogues of condensing boiler manufacturers, condensation will occur in the $80 / 60{ }^{\circ} \mathrm{C}$ mode. However, for a return water temperature of $60{ }^{\circ} \mathrm{C}$, the flue gas must have an outlet temperature of at least $70{ }^{\circ} \mathrm{C}$. Considering this, together 
with the data on the excess air from Tab. 3, one can conclude that no condensation will occur. It is important to emphasize that with an increase in the amount of excess air, the temperature of water vapour condensation decreases, so that the combustion with excess air values of up to 1.1 would result in a condensation temperature higher than $56{ }^{\circ} \mathrm{C}$. In this case, combined with the existence of a low temperature consumer, the efficiency of the condensing boiler would be almost $100 \%$.

\section{REFERENCES}

[1] Che, D., Liu, Y., \& Gao, C. (2004). Evaluation of retrofitting a conventional natural gas fired boiler into a condensing boiler. Energy Conversion and Management, 45(20), 32513266 . https://doi.org/10.1016/j.enconman.2004.01.004

[2] Kuck, J. (1996). Efficiency of vapour-pump-equipped condensing boilers. Applied Thermal Engineering, 16(3), 233-244. https://doi.org/10.1016/1359-4311(95)00067-4

[3] Zhao, X., Fu, L., Yuan, W., Li, F., \& Li, Q. (2016). The Potential and Approach of Flue Gas Waste Heat Utilization of Natural Gas for Space Heating. Procedia Engineering, 146, 494-503. https://doi.org/10.1016/j.proeng.2016.06.380

[4] Cirillo, E., Lazzarin, R., Piccininni, F., \& Caliari, R. (1990). Energy analysis of a central domestic hot water heating system equipped with condensing boilers. International journal of energy research, 14(1), 73-81. https://doi.org/10.1002/er.4440140109

[5] Hasan, A., Kurnitski, J., \& Jokiranta, K. (2009). A combined low temperature water heating system consisting of radiators and floor heating. Energy Build, 41, 470-479. https://doi.org/10.1016/j.enbuild.2008.11.016

[6] Chen, Q., Finney, K., Li, H., Zhang, X., Zhou, J., \& Sharifi, V. (2012), Swithenbank Jim. Condensing boiler applications in the process industry. Applied Energy, 89(1), 30-36. https://doi.org/10.1016/j.apenergy.2010.11.020

[7] Stephan, K. \& Mayinger, F. (1998). Thermodynamik, Band 1: Einstoffsysteme, 15. Auflage. Springer Verlag, Berlin, ISBN 978-3-642-30098-1

\section{Contact information:}

Marija ŽIVIĆ, full professor

(Corresponding author)

Mechanical Engineering Faculty in Slavonski Brod,

J. J. Strossmayer University of Osijek

Trg Ivane Brlić Mažuranić 2, 35000 Slavonski Brod, Croatia

mzivic@sfsb.hr

Antun GALOVIĆ, full professor

Faculty of Mechanical Engineering and Naval Architecture,

University of Zagreb,

Ivana Lučića 5, 10000 Zagreb, Croatia

agalovic@fsb.hr

Jurij AVSEC, full professor

Faculty of Energy Technology,

University of Maribor,

Hočevarjev trg 1, SI-8270 Krško, Slovenia

jurij.avsec@um.si

Antun BARAC, mag. ing. mech

Mechanical Engineering Faculty in Slavonski Brod,

J. J. Strossmayer University of Osijek,

Trg Ivane Brlić Mažuranić 2, 35000 Slavonski Brod, Croatia

abarac@sfsb.hr 